\title{
Signo de la nariz del oso hormiguero
}

\section{Anteater's Nose Sign}

\author{
Flavia Barrera ${ }^{1}$ Roxana Rosado ${ }^{1}$ Claudio Milicchio $^{1}$ \\ 1 Servicio de Diagnóstico por Imágenes, Imágenes MDQ, Mar del \\ Plata, Buenos Aires, Argentina \\ Rev Argent Radiol 2019;83:42-43.
}

El signo de la nariz del oso hormiguero tiene lugar en la radiografía $(\mathrm{Rx})$ lateral de pie cuando existe una barra tarsal calcáneo-escafoidea. En esos casos, el proceso anterior del calcáneo se encuentra elongado hacia el margen lateral del escafoides tarsiano (-Fig. 1), asemejándose a la nariz de un oso hormiguero. ${ }^{1}$ El signo fue descrito por primera vez por Oestreich y col., en $1987 .{ }^{1}$

La barra tarsal calcáneo-escafoidea se debe a una alteración en la diferenciación y segmentación del mesénquima primitivo, ${ }^{2}$ dando como resultado una fusión ósea, cartilaginosa o fibrosa anormal entre los huesos del tarso. Dentro de las barras tarsales es la coalición más común, presentándose en aproximadamente el $53 \%$ de los casos. ${ }^{3} \mathrm{La}$ presentación clínica es muy amplia, siendo sintomático solo el $25 \%$ de los casos, la mayoría entre los 8 y 12 años de edad, cuando se osifica la barra cartilaginosa calcáneo-escafoidea. ${ }^{3}$ El paciente puede presentar desde dolor de pies hasta deformidad progresiva en valgo con aplanamiento del arco
Address for correspondence Flavia Barrera, MD, Servicio de Diagnóstico por Imágenes, Imágenes MDQ, Mar del Plata, Buenos Aires, Argentina (e-mail: flaviabarrera03@gmail.com).

longitudinal, asociado o no a limitación o ausencia del movimiento subtalar, síndrome del túnel tarsiano y espasmo del tendón peroneo. ${ }^{4}$

Los pacientes con deformidad progresiva son los más expuestos a desarrollar artrosis tardía, ya que modifican la marcha aumentando el estrés en las articulaciones afectadas y vecinas. Los estudios por imágenes revisten gran importancia en el diagnóstico y caracterización de las barras tarsales.

La articulación anormal entre los huesos calcáneo y escafoides puede observarse en las radiografías laterales del pie en bipedestación, siendo aún más evidente en proyecciones oblicuas internas a $45^{\circ} .5$

La tomografía computada (TC), es el estudio de elección para confirmar el diagnóstico. Resultan de gran utilidad las reconstrucciones multiplanares, fundamentalmente en los planos coronal y sagital $^{3-5}$ (-Fig. 2). La resonancia magnética cobra importancia en la identificación de posibles coaliciones fibrosas. Otros hallazgos que pueden reconocerse

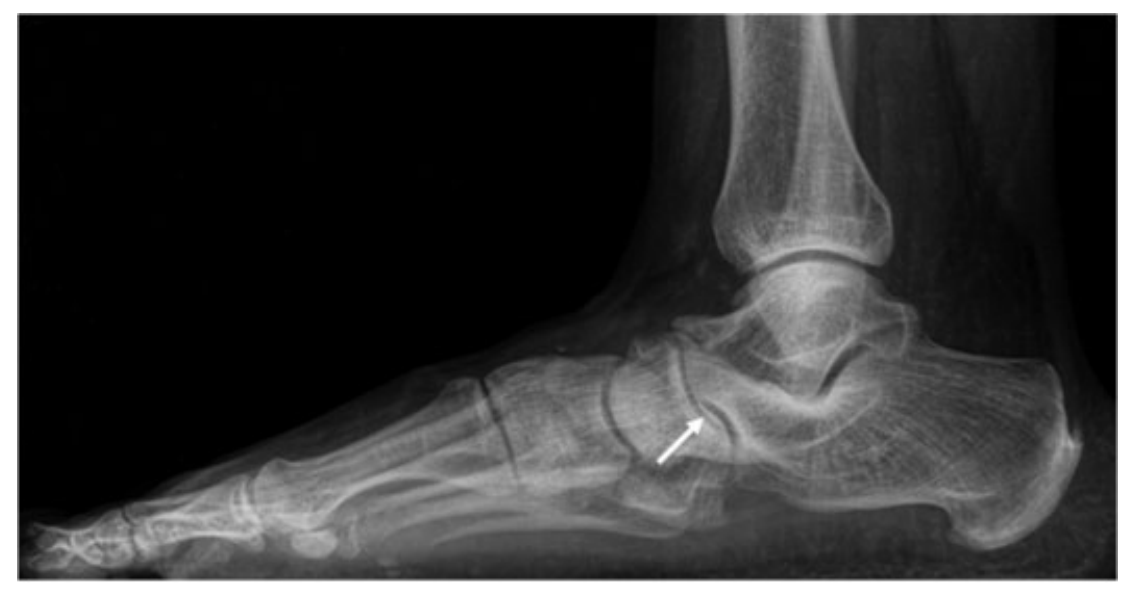

Fig. 1 Radiografía perfil de tobillo. Barra ósea tarsal calcáneo-escafoidea. Signo de la nariz del oso hormiguero (flecha).

received

April 27, 2018

accepted

August 15, 2018

published online

February 22, 2019
DOI https://doi.org/

$10.1055 / \mathrm{s}-0038-1673697$.

ISSN 1852-9992.
Copyright @ 2019, Sociedad Argentina de Radiología. Publicado por Thieme Revinter Publicações Ltda., Rio de Janeiro, Brazil. Todos los derechos reservados.

\section{License terms}

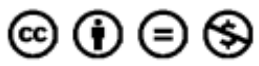



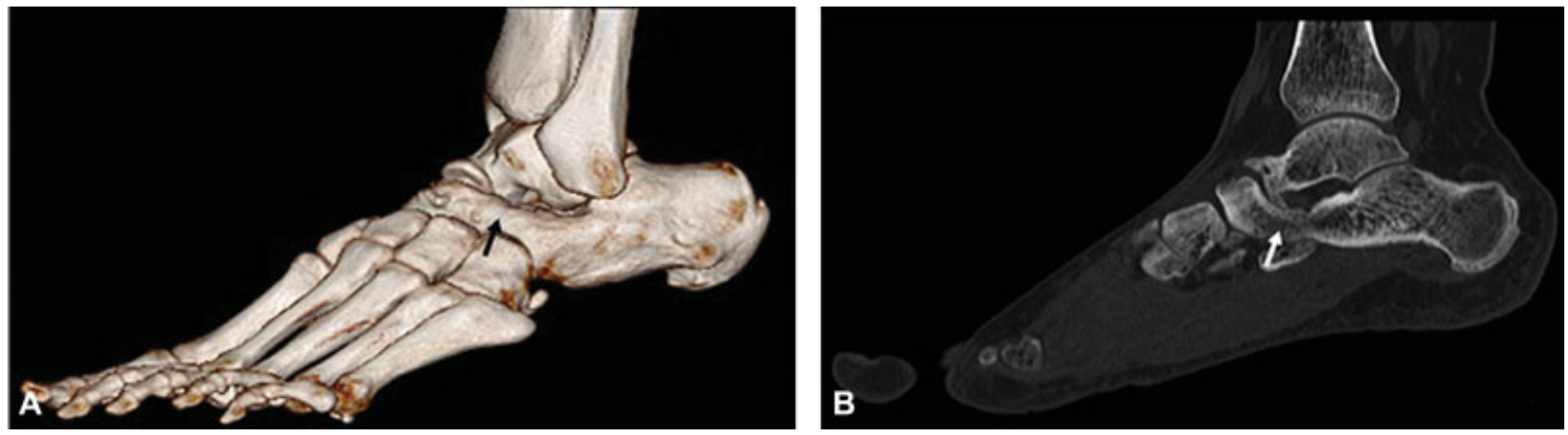

Fig. 2 Tomografía computada con reconstrucción 3D (A) y reconstrucción multiplanar (MPR) en plano sagital de tobillo (B). Barra ósea tarsal calcáneo-escafoidea (flechas).
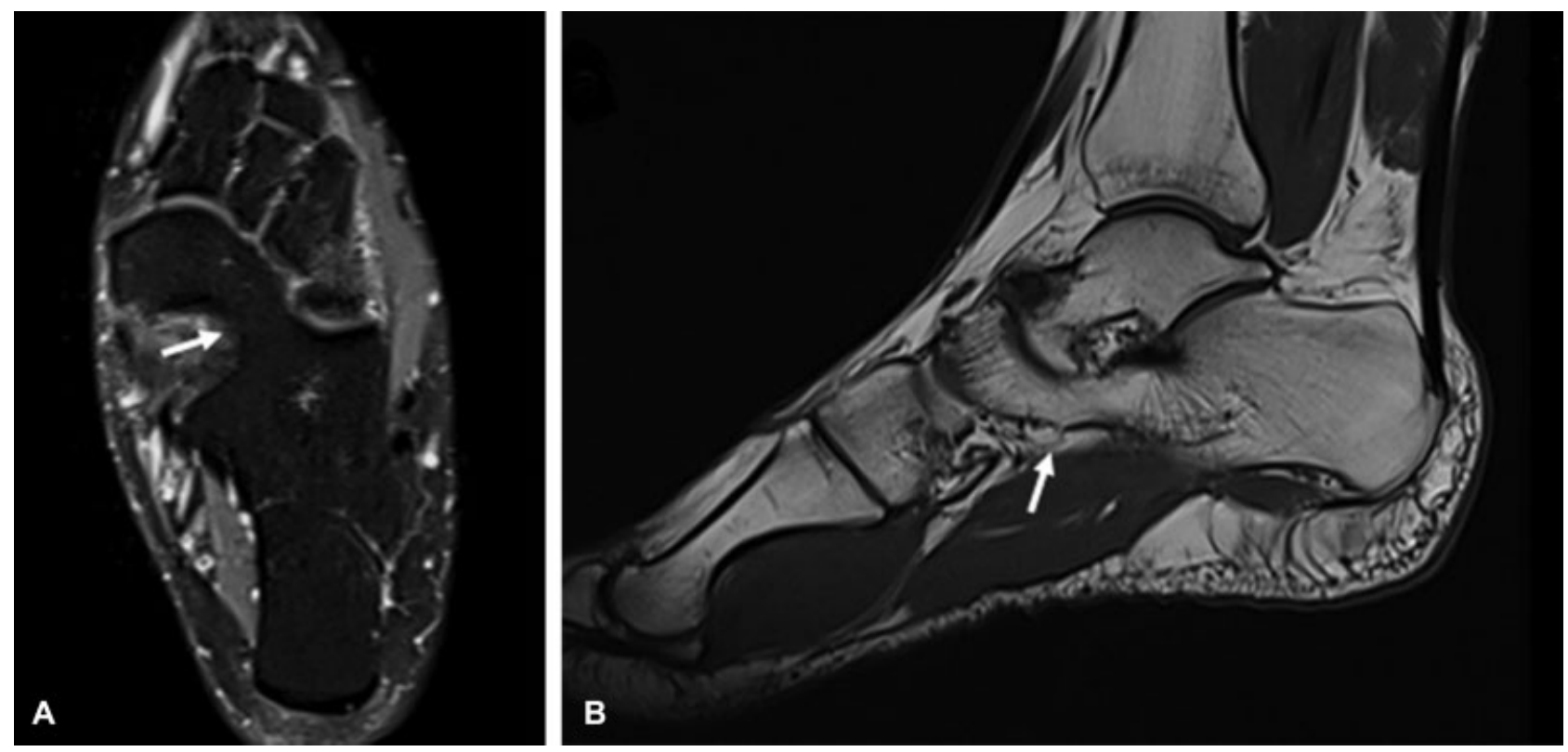

Fig. 3 Resonancia magnética de tobillo en plano axial STIR (A) y en plano sagital potenciada en T1 (B). Barra ósea tarsal calcáneo-escafoidea.

son la presencia de edema óseo y cambios degenerativos de las articulaciones adyacentes ${ }^{3,5}$ (-Fig. $\mathbf{3}$ ).

Dentro de los falsos positivos descritos existen condiciones adquiridas que pueden simular coaliciones congénitas, como es el caso de enfermedades malignas, inflamaciones, fracturas intraarticulares y osteonecrosis. ${ }^{3}$ Los pacientes que presentan síntomas son los que requieren tratamiento. En primera instancia se realiza manejo conservador, con plantillas, a fin de mejorar la alineación y disminuir el dolor. ${ }^{5}$

El manejo quirúrgico debe considerarse en todos los pacientes con dolor persistente o recurrente tras el tratamiento conservador. ${ }^{5}$

Declaración de Conflicos de Interés

Los autores declaran no tener ningún conflicto de interés.
Financiación

Imágenes MDQ.

\section{Bibliografía}

1 Chapman VM. The anteater nose sign. Radiology 2007;245(02): 604-605

2 Newman JS, Newberg AH. Congenital tarsal coalition: multimodality evaluation with emphasis on CT and MR imaging. Radiographics 2000;20(02):321-332, quiz 526-527, 532

3 Efstathopoulos N, Nikolaou V, Lazarettos J, Triantopoulou Ch, Plessas S. Calcaneonavicular coalition. A case report and a literature review article. Eur J Orthop Surg Traumatol 2006;16:70-74

4 Crim JR, Kjeldsberg KM. Radiographic diagnosis of tarsal coalition. AJR Am J Roentgenol 2004;182(02):323-328

5 Oestreich AE, Mize WA, Crawford AH, Morgan RC Jr. The "anteater nose": a direct sign of calcaneonavicular coalition on the lateral radiograph. J Pediatr Orthop 1987;7(06):709-711 